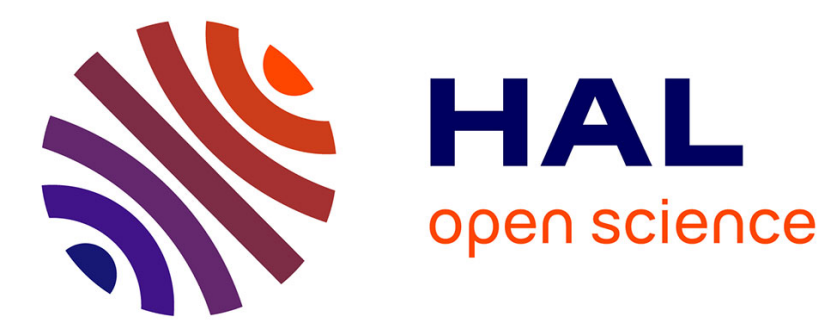

\title{
Identification of sustainable dietary patterns by a multicriteria approach in the NutriNet-Sante cohort
}

Louise Seconda, Julia Baudry, Benjamin Allès, Louis-Georges Soler, Serge Hercberg, Brigitte Langevin, Philippe Pointereau, Denis Lairon, Emmanuelle Kesse-Guyot

\section{To cite this version:}

Louise Seconda, Julia Baudry, Benjamin Allès, Louis-Georges Soler, Serge Hercberg, et al.. Identification of sustainable dietary patterns by a multicriteria approach in the NutriNet-Sante cohort. Journal of Cleaner Production, 2018, 196, pp.1256-1265. 10.1016/j.jclepro.2018.06.143 . hal-02068144

\section{HAL Id: hal-02068144 \\ https://hal-amu.archives-ouvertes.fr/hal-02068144}

Submitted on 2 May 2019

HAL is a multi-disciplinary open access archive for the deposit and dissemination of scientific research documents, whether they are published or not. The documents may come from teaching and research institutions in France or abroad, or from public or private research centers.
L'archive ouverte pluridisciplinaire HAL, est destinée au dépôt et à la diffusion de documents scientifiques de niveau recherche, publiés ou non, émanant des établissements d'enseignement et de recherche français ou étrangers, des laboratoires publics ou privés. 


\title{
Identification of sustainable dietary patterns by a multicriteria approach in the NutriNet-Santé cohort
}

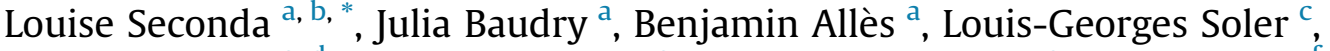 \\ Serge Hercberg ${ }^{a, d}$, Brigitte Langevin ${ }^{e}$, Philippe Pointereau ${ }^{e}$, Denis Lairon ${ }^{\mathrm{f}}$, \\ Emmanuelle Kesse-Guyot ${ }^{\mathrm{a}}$ \\ ${ }^{a}$ EREN, Université Paris 13, INSERM (U1153), INRA (U1125), Centre d'Epidémiologie et Statistiques Paris Cité, CNAM, COMUE Sorbonne-Paris-Cité, 74 rue \\ Marcel Cachin, 93017 Bobigny, France \\ b ADEME (Agence de l'Environnement et de la Maîtrise de l'Energie), 20 avenue du Grésillé BP 90406, 49004 Angers, France \\ ${ }^{\mathrm{c}}$ Aliss, INRA (UR 1303), 65 Boulevard de Brandebourg, 94200 Ivry-sur-Seine, France \\ d Département de Santé Publique, Hôpital Avicenne, 125 rue de Stalingrad, 93000 Bobigny, France \\ e Solagro, 75 Voie Toec, 31000 Toulouse, France \\ ${ }^{\mathrm{f}}$ NORT (Nutrition, Obésité et Risque Thrombotique), Aix Marseille Université, INSERM (U1062), INRA (U1260), Faculté de Médicine de la Timone, 27 \\ boulevard Jean Moulin, 13005 Marseille, France
}

Keywords:

Sustainability

Environment

Greenhouse gas

Nutrition

Organic food

Dietary pattern

\begin{abstract}
A B S T R A C T
In the context of the increasingly damaging impact of agro-food systems on human health and the environment, this study aimed to evaluate the sustainability of current dietary patterns using multicriteria analysis to characterize consumers with different dietary patterns. In a sample of 29,413 participants of the NutriNet-Santé Study, total and organic food intakes of 264 items gathered in 17 food groups were evaluated using a food frequency questionnaire. Eight sustainability indicators were assessed individually. To identify combinations of food groups explaining the maximum variation in the sustainability indicators, we applied reduced rank regression with food groups as predictors and sustainability indicators as response variables. Then, the first two RRR-derived factors were used to classify participants using an ascending hierarchical classification. Six clusters were identified, among then one cluster $(\mathrm{N}=23.07 \%)$ presented a good compromise between all the sustainable dimensions. Indeed, their diets emitted on average $36 \%$ less greenhouses gas, included 30\% more organic food and exhibited a close level of affordability compared to the average. The dietary composition in this group, were characterized by $-58 \%$ of red meat, $-37 \%$ of white meat, $-25 \%$ of cheese but $+15 \%$ of fruits, $+15 \%$ of vegetable and a similar contribution of fish and starches, compared to the sample average. Finally, this study showed that in the current food system context, the observed diets rarely meet all sustainability criteria. Oppositions between healthy, eco-friendly and affordability often remain. However, we observed some diets with high compatibility with all sustainable indicators selected for the study. Thus sustainable diets are emerging and should be promoted. However, it would be relevant to conduct additional research in other population to estimate acceptability.
\end{abstract}

* Corresponding author. Equipe de Recherche en Epidémiologie Nutritionnelle (EREN), Université Paris 13, SMBH, 74 rue Marcel Cachin, 93017 Bobigny, France.

E-mail addresses: 1.seconda@eren.smbh.univ-paris13.fr (L. Seconda), j.baudry@ eren.smbh.univ-paris13.fr (J. Baudry), b.alles@eren.smbh.univ-paris13.fr (B. Allès), louis-georges.soler@inra.fr (L.-G. Soler), s.hercberg@uren.smbh.univ-paris13.fr (S. Hercberg), b.langevin@laposte.net (B. Langevin), philippe.pointereau@solagro. asso.fr (P. Pointereau), denis.lairon@orange.fr (D. Lairon), e.kesse@eren.smbh. univ-paris13.fr (E. Kesse-Guyot).

\section{Introduction}

Concern about the ability of the overall agricultural system to sustainably feed the world's population is growing (Birt et al., 2017). In this context, the number of studies identifying sustainable diets has concomitantly increased (Perignon et al., 2017; Aleksandrowicz et al., 2016; Hallström et al., 2015; Auestad and Fulgoni, 2015; Jones et al., 2016). Indeed, substantial adoption of sustainable diets (as defined by the FAO) may help to respond to the forthcoming challenges of population growth, climate mitigation, 


\begin{tabular}{|ll|}
\hline \multicolumn{2}{|c|}{ Abbreviations: } \\
ANOVA & Analysis of Variance \\
ANCOVA & Analysis of Covariance \\
BMI & Body Mass Index \\
CED & Cumulative Energy Demand \\
CI & Confidence Interval \\
FAO & Food and Agriculture Organization \\
FFQ & Semi-Quantitative Frequency Questionnaire \\
GHGEs & Greenhouse Gas Emissions \\
IPAQ & International Physical Activity Questionnaires \\
Org-FFQ & Organic Food Semi-Quantitative Frequency \\
& Questionnaire \\
PANDiet: & Diet Quality Index Based on the Probability of \\
& Adequate Nutrient Intake \\
RRR & Reduced Rank Regression \\
\hline
\end{tabular}

nutritional transition, and global food security (Birt et al., 2017; Sustainable diets and Biodiversity - Directions and solutions for policy, 2016; Springmann et al., 2016). In recent years, there has been growing interest in both identifying levers to make a diet more sustainable and also in comparing more sustainable diets identified in the general population.

The first approach was based on modelling and aimed at identifying levers to render the diets more sustainable. Most of these studies have established that the reduction of meat consumption and energy intake are primary factors to mitigate the environmental impacts and improve the sustainability of diets (Perignon et al., 2017). However, modelling is based on a predefined hypothesis, which inherently determines the results. For example, in linear programming methods, constraints on items intake are sometimes added to minimize the deviation of the observed diets to ensure acceptable solutions, which are more similar to current diets (Darmon et al., 2002; van Dooren et al., 2015). However, there has been no reliable evidence showing that the adoption of a sustainable diet does not require profound changes in dietary patterns. Moreover, it remains difficult to account for all the substitutions within food group consumption with linear programming methods.

The second approach have directly compared and analysed the variability of diets observed in the general population. Some studies have compared the sustainability indicators of specific diets, such as vegetarian, vegan or Mediterranean diets (Hallström et al., 2015; Tilman and Clark, 2014; Aston et al., 2012; Scarborough et al., 2014; Soret et al., 2014; Castañé and Antón, 2017; Sáez-Almendros et al., 2013; Pairotti et al., 2015). A reduction of environmental impacts (Greenhouse Gas Emissions (GHGEs), land use or energy consumption) could be achieved the most of the time by shifting to these dietary patterns. However, recommending a vegan or vegetarian diets for sustainable purpose in France where meat and cheese are part of the cultural and territorial heritage appears difficult. Moreover, the adoption of these diets could lead to potential nutrients deficiency (vitamin B12 and D, iron, calcium, EPA, and DHA), which questions consistency with the sustainability of these diets (Aleksandrowicz et al., 2016; Castañé and Antón, 2017; van Dooren et al., 2014). Others have compared groups of participants according to a single sustainability indicator, such as greenhouse gas emissions (Temme et al., 2015), organic food consumption (Treu et al., 2017; Baudry et al., 2015), or nutritional quality score (Monsivais et al., 2015). The latter focused on the nutritional or environmental dimensions, but the affordability and socioeconomic aspects have been rarely investigated
(Perignon et al., 2017; Jones et al., 2016). Nonetheless, the affordability and acceptance of alternative diets are crucial for their adoption by a significant part of the population. Moreover, the use of only one environmental indicator (e.g., greenhouse gas emissions or land use) ignores other important features that are potentially affected by diets (Auestad and Fulgoni, 2015; Jones et al., 2016).

Thus, despite the growing interest in this topic, the identification of more sustainable diets remains challenging because of the use of few indicators and the numerous a priori hypotheses. The purpose of this study was to assess and compare the sustainability of diets in a large sample of French adults from the NutriNet-Santé cohort by a multicriteria approach. The selected indicators are related to nutrition (energy density of the diet, adequacy and moderation sub-scores of PANDiet), the environment (greenhouse gas emissions, primary energy demand, land occupation, and organic food contribution as a proxy of the use of chemical products), and the economy (the share of the budget dedicated to food).

\section{Materials and methods}

\subsection{Study population}

The sample was composed of participants in the NutriNet-Santé Study, a large web-based observational cohort of volunteers aged 18 years and older, which was launched in France in May 2009 and whose recruitment is still in progress (Hercberg et al., 2010). At inclusion, the participants completed a set of five web-based questionnaires about socio-demographic conditions, anthropometry, lifestyles, dietary intake (using repeated 24 -h records) and physical activity along with health status. During follow up, participants were invited to update these data at least every year and fill in optional complementary questionnaires, to develop ancillary protocols. This study was conducted in accordance with the Declaration of Helsinki, and all procedures were approved by the Institutional Review Board of the French Institute for Health and Medical Research (IRB Inserm 0000388FWA00005831) and the Commission Nationale de l'Informatique et des Libertés (CNIL 908450 and 909216). All participants provided informed consent with an electronic signature. The Clinical Trials number is NCT03335644.

\subsection{Dietary data assessment and computation of dietary indexes}

In July 2014, an optional organic semi-quantitative food frequency questionnaire (Org-FFQ) based on a previously validated FFQ was administered to participants (Baudry et al., 2015; KesseGuyot et al., 2010). The participants were invited to report their consumption frequencies over the past year, using yearly, monthly, weekly or daily frequencies and their usual portion size (described as typical household measurements or using colour photographs) for 264 items. Food intakes were estimated by multiplying the frequency of consumption by the usual portion size. The 264 items were grouped into 17 food groups (Supplemental Table 1).

For each item, the participants were asked to report their frequency of consumption in its organic form (referring to European Union-certified organic labelling) through a 5-point ordinal scale. Organic food intake was estimated for each item by applying a weight of $0,0.25,0.50,0.75$ and 1 to the five respective modalities: never, rarely, half of the time, often and always, respectively (Baudry et al., 2015).

A food composition database was built especially for the items presented in the Org-FFQ using the original NutriNet-Santé composition table (Nutrinet-Santé, 2013) without accounting for 
some potential differences in the nutritional values for organic and conventional food, allowing the estimation of individual daily nutrient intake. For mixed dishes standard recipes (based on the 24 h dietary records tool of the NutriNet-Santé study) validated by dieticians were used to assess the food composition. The energy density of the diet, the percentage of organic food consumption in the diet and the moderate and adequacy sub-scores of PANDiet (Verger et al., 2012) were computed. Several nutritional quality indexes are proposed in the literature, however the PANDiet is directly based on nutrient intake recommendations and its assessment mobilizes the most of current knowledges on nutrients intakes. Indeed, the PANDiet is composed of adequacy probabilities for 24 nutrients, using French national nutritional recommendations, groups into two sub-scores. The adequacy sub-score was composed of nutrients (protein, total carbohydrate, total fat, polyunsaturated fatty acid, n-3 fatty acids, n-6 fatty acids, cholesterol, fibre, vitamins A, B1, B2, B3, B5, B6,B9, B12, C, D and E, Ca, Mg, Zn, P, $\mathrm{K}, \mathrm{Fe}$, iodine, Se) which intake should be above a reference value, while the moderation sub-score was for items (Protein, total carbohydrate, total fat, added simple carbohydrate, saturated fatty acid, cholesterol and $\mathrm{Na}$ ) for which the usual intake should not exceed a reference value. The exhaustive description has been explained elsewhere (Verger et al., 2012).

\subsection{Assessment of indicators of affordability}

At the same time as the Org-FFQ administration (in July 2014), participants in the NutriNet-Santé study were also invited to complete a questionnaire including questions about the place where the food was purchased for different food groups. Meanwhile, prices of the 264 items accounting for the mode of production (organic vs. conventional) and the place of purchase (supermarket, hard discount supermarket, grocery store, artisans shop, farm shop, AMAPs (Associations Supporting Small Farming), street market, or producers shop) were allocated as previously described (Seconda et al., 2017). Food prices were obtained from the 2012 KANTAR Worldpanel purchase database and a complementary survey carried out by members of the Bioconsom'acteurs association to provide additional prices in specific channels (e.g., short supply chain) (Seconda et al., 2017). Finally, the individual monetary cost of the diet was computed by multiplying the price $(€ / g)$ by the food quantity consumed $(\mathrm{g} / \mathrm{d})$ accounting for the place of purchase and the mode of production.

A common measure of diet affordability is the share of budget dedicated to the food purchase (Gustafson et al., 2016; Barosh et al., 2014; Lee et al., 2016). We assessed this indicator as the ratio between the total monetary cost of the diet and the income per household unit. As the incomes per household unit were in categories, the median of each class was used, and arbitrary values were allocated for the extreme classes $(765 € /$ month and household unit for individuals reporting less than $900 € /$ month or $5480 € /$ month and by household unit for individuals reporting more than $3700 € \mid$ month or $2500 € /$ month for non-respondents).

\subsection{Environmental diet impact assessment}

Environmental indicators, namely, GHGEs (greenhouse gas emissions in $\mathrm{kg} \mathrm{CO} 2 \mathrm{eq} / \mathrm{kg}$ ), $\mathrm{CED}$ (cumulative energy demand in $\mathrm{MJ} /$ $\mathrm{kg}$ ) and land occupation (in $\mathrm{m}^{2} / \mathrm{kg}$ ), of the production of each OrgFFQ item, accounting for the mode of production (conventional vs. organic), were calculated. The methodological approaches are described in detail elsewhere (Seconda et al., 2018). Briefly, the perimeter of environmental impact assessment included the upstream processes such as the production of inputs or energy provision, while conditioning, transport, processing, storage and recycling were excluded. Environmental impacts of raw products Data were derived from the DIALECTE database, a comprehensive tool developed by Solagro (2017) to assess the environmental performance of farms. We completed the environmental database with published literature data, to obtain the environmental impact in organic and conventional of 92 raw agricultural products. Then, we conducted a set of conversions in order to compute environmental impacts for food items of the food frequency questionnaire from those assess for raw agricultural products. Indeed, the items were decomposed into ingredients. The environmental impacts of ingredients (organic and conventional) were assessed from raw products by applying an economic allocation (accounting for coproducts) and cooking and edibility coefficients.

The diet-related GHGEs, CED and land occupation were assessed at the individual level by multiplying the food quantity consumed (g/d) by the environmental impacts accounting for the mode of food production.

\subsection{Covariates}

The inclusion and yearly updated questionnaires provided sociodemographic and lifestyle information. The data closest to the date of completion of the Org-FFQ were used.

Sociodemographic and lifestyle characteristics included sex, age, highest achieved degree (<high school diploma, high school diploma and post-secondary graduate), smoking status (former, occasional, current and never smokers), location (rural community, urban unit with a population smaller than 20,000 inhabitants, between 20,000 and 200,000 inhabitants and higher than 200,000 inhabitants), monthly income per household unit ( $<1200$ euros, between 1200 and 1800 euros, between 1800 and 2700 euros and $>2700$ euros per household unit) obtained using the income by month in the household and the composition of the household, the reported practice of vegetarian (a diet that did not include any meat) or vegan diets (a diet that excluded all foods of animal origin), alcohol consumption status (abstainers, moderate drinkers ( $<20 \mathrm{~g} /$ day for women and $<30 \mathrm{~g} /$ day for men) and high drinkers), and level of physical activity ( $<30 \mathrm{~min} /$ day, 30-60 min/day and $>60 \mathrm{~min} / \mathrm{d}$ ) as measured by the IPAQ (International Physical Activity Questionnaires (Craig et al., 2016; Hallal and Victora, 2004)).

Weight and height were collected by a health operator or medical doctor or from self-measurement guided by standardized procedures, which were used to compute the BMI (body mass index $\left(\mathrm{kg} / \mathrm{m}^{2}\right)$ ). Then, the participants were gathered into 4 groups (underweight $\left(18.5 \mathrm{~kg} / \mathrm{m}^{2} \leq \mathrm{BMI}\right)$, normal-weighted, overweight $\left(25 \leq \mathrm{BMI}<30 \mathrm{~kg} / \mathrm{m}^{2}\right)$, and obese $\left.\left(\mathrm{BMI} \geq 30 \mathrm{~kg} / \mathrm{m}^{2}\right)\right)$ according to the international BMI classification of the World Health Organization (Organisation Mondiale de la Santé (OMS), 2017).

\subsection{Statistical analyses}

For the present analyses, we selected participants who completed the Org-FFQ $(n=37,685)$. Under or over-reporters (identified by a ratio of energy intake to energy requirement (estimated with the Schofield equations (Schofield, 1984)) below or above the previously defined cut-offs) (Schofield, 1984) were excluded $(n=2109)$, as were those with missing covariates $(n=391)$. Finally, the subjects who did not complete the place of purchase questionnaire to assess the monetary cost of the diet were also excluded, leading to a final sample of 29,413 participants.

To identify the dietary patterns, an RRR (reduced rank regression) procedure, as described by Hoffman et al. (Hoffmann, 2004), was used. This method allows determining linear functions of 
predictors (food groups) that maximize the explained variation in a set of responses (sustainability indicators). The RRR model was performed using 8 sustainability indicators (Table 1) as response variables: GHGES, CED, land occupational, organic food consumption ratio, diet density, PANDiet adequacy sub-score, PANDiet moderation sub-score and the share of the budget allocated to food. The choice of these eight indicators was a compromise between information from the scientific literature (Perignon et al., 2017; Aleksandrowicz et al., 2016; Auestad and Fulgoni, 2015), the available data in our database and predominately the possibility to estimate the indicator at an individual level a main objective of our work. Additionally, we tried to cover the four sustainable domains: environment, nutrition, economy and socio-cultural, to be the most representative. The sustainability dimensions measured by each indicator were described in Table 1 . The daily consumption $(\mathrm{g} / \mathrm{d})$ of 17 food groups (vegetables, fruit, dried fruits and nuts, fish, ruminant meat, other meat (including processed meat), eggs, fresh dairy products, cheese, fatty and/or sweet products, starches, whole grain, oil, butter, mixed dishes, soya and alcoholic beverages) adjusted for total energy intake using the residual method (Willett and Stampfer, 1986), were included as predictors.

To test the reproducibility of the method, we assessed the
Pearson correlation coefficient between the first and second factors of the RRR procedure extracted from the whole sample and from a random sample, including half of the population (20 replications).

In the second step, we performed a two-step clustering procedure based on the first two RRR-extracted factors. First, we performed a hierarchical ascendant classification using the Ward procedure. The dendrogram (graphical method), statistical quality indicators of clustering ( $\mathrm{R}^{2}$ semi-partial and pseudo $\mathrm{F}$ ) and interpretability criteria (Baudry et al., 2016) led to retaining a partition with 6 clusters. Then, a non-hierarchical K-means procedure using the barycenter of the cluster identified in the first step as a seed was performed.

The means and 95\% confidence interval (CI) of the 8 sustainability indicators and 17 food group intakes used for the RRR analysis were calculated for each cluster. The averages of the food group consumptions were adjusted for total energy intake with the residual methods (Willett and Stampfer, 1986). Participant characteristics across the clusters were assessed by ANOVA and ANCOVA as appropriate. Socio-demographic and lifestyle characteristics were compared between the clusters, and the $P$ value was based on the $\chi^{2}$ test. The type I error was set at $5 \%$ for all the statistical tests. Post hoc differences in the adjusted means across the

Table 1

Overview of the indicators of sustainability considered as response variables.

\begin{tabular}{|c|c|c|c|c|}
\hline Indicators & $\begin{array}{l}\text { Sustainability dimension } \\
\text { measured by the indicator }\end{array}$ & Definition & Indicator assessment & Data sources \\
\hline $\begin{array}{l}\text { Cumulative energy } \\
\text { demand }(\mathrm{Mj} / \mathrm{y})\end{array}$ & $\begin{array}{l}\text { Environment: partial } \\
\text { reflection of resource } \\
\text { depletion (in particular } \\
\text { fossil energy) }\end{array}$ & $\begin{array}{l}\text { Cumulative energy demand included } \\
\text { consumption of renewable and } \\
\text { unrenewable energy at the farm level as } \\
\text { defined by the CED method }\end{array}$ & $\begin{array}{l}\text { Assessment of the indicators at the farm } \\
\text { level, taking into account the mode of } \\
\text { food production (conventional vs. } \\
\text { organic) and the further allocation of }\end{array}$ & $\begin{array}{l}\text { DIALECTE database completed } \\
\text { by data available in the } \\
\text { literature and collected using } \\
\text { the Org-FFQ (2014) }\end{array}$ \\
\hline $\begin{array}{l}\text { Greenhouse gas } \\
\text { emissions }(\mathrm{kg} \\
\left.\mathrm{CO}_{2 \mathrm{eq}} / \mathrm{y}\right)\end{array}$ & $\begin{array}{l}\text { Environment: climate } \\
\text { change }\end{array}$ & $\begin{array}{l}\text { Quantity of carbon dioxide, methane } \\
\text { and nitrous oxide emissions at the farm } \\
\text { level, weighted by their } 100 \text {-year global } \\
\text { warming potential, defined by the IPCC } \\
\text { (The Intergovernmental Panel on } \\
\text { Climate Change). }\end{array}$ & $\begin{array}{l}\text { economic, mass, cooking and edibility } \\
\text { factor }\end{array}$ & \\
\hline $\begin{array}{l}\text { Land occupation } \\
\qquad\left(\mathrm{m}^{2} / \mathrm{y}\right)\end{array}$ & $\begin{array}{l}\text { Environment: resource } \\
\text { depletion }\end{array}$ & $\begin{array}{l}\text { Area that is required to produce raw } \\
\text { agricultural products, without } \\
\text { considering the duration of land use. }\end{array}$ & & \\
\hline $\begin{array}{l}\text { Organic food ratio } \\
\text { (\%) }\end{array}$ & $\begin{array}{l}\text { Environment and } \\
\text { Sociocultural: preservation } \\
\text { of natural resources }\end{array}$ & $\begin{array}{l}\text { Percentage of food organic } \\
\text { consumption (referred to European } \\
\text { Union labelling) }\end{array}$ & $\begin{array}{l}\text { Division of the total organic food intake } \\
\text { (g/day) by the total intake (g/day), } \\
\text { excluding water and zero-calorie } \\
\text { beverages. }\end{array}$ & Org-FFQ (2014) \\
\hline $\begin{array}{l}\text { Density (kcal/ } \\
\quad 100 \mathrm{~g})\end{array}$ & $\begin{array}{l}\text { Nutrition: consumption of } \\
\text { energy-dense food }\end{array}$ & Available energy per $100 \mathrm{~g}$ of diet & $\begin{array}{l}\text { Division between the daily energy } \\
\text { intake by the daily weight consumed } \\
\text { (excluding zero-calorie beverages), } \\
\text { multiplied by } 100 \text {. }\end{array}$ & $\begin{array}{l}\text { Org-FFQ (2014) and NutriNet- } \\
\text { Santé consumed (excluding } \\
(2014)\end{array}$ \\
\hline $\begin{array}{l}\text { Adequacy sub- } \\
\text { score }(/ 100)\end{array}$ & $\begin{array}{l}\text { Nutrition: adequacy } \\
\text { between nutrient intake } \\
\text { and French } \\
\text { recommendations }\end{array}$ & $\begin{array}{l}\text { PANDiet sub-score assessing whether } \\
\text { the diet satisfied the requirement. }\end{array}$ & $\begin{array}{l}\text { Average probability of adequate* intake } \\
\text { for } 21 \text { nutrients multiplied by } 100 .\end{array}$ & \\
\hline $\begin{array}{l}\text { Moderation sub- } \\
\text { score }(/ 100)\end{array}$ & $\begin{array}{l}\text { Nutrition: adequacy } \\
\text { between nutrient intake } \\
\text { and French } \\
\text { recommendations }\end{array}$ & $\begin{array}{l}\text { PANDiet sub-score assessing whether } \\
\text { the diet was not excessive and elicited } \\
\text { adverse health effects. }\end{array}$ & $\begin{array}{l}\text { Average probability* of adequacy for } 6 \\
\text { nutrients for which the usual intake } \\
\text { should not exceed the reference value } \\
\text { (the upper tolerable limit of intake or } \\
\text { upper bounds of the acceptable } \\
\text { distribution range) multiplied by } 100 \\
\text { and a penalty value system for other } \\
\text { vitamins and minerals with available } \\
\text { upper tolerable limits where the risk of } \\
\text { excessive intake is lower. }\end{array}$ & \\
\hline $\begin{array}{l}\text { Share of budget } \\
\text { dedicated to } \\
\text { food }\end{array}$ & $\begin{array}{l}\text { Economy: partial reflection } \\
\text { of the diet affordability }\end{array}$ & $\begin{array}{l}\text { Food expenditure divided by the } \\
\text { income reported by the consumption } \\
\text { unit in the household. }\end{array}$ & $\begin{array}{l}\text { Food price according to the place of } \\
\text { purchase and production mode } \\
\text { database were built with } 2012 \text { KANTAR } \\
\text { data and prices collected by members of } \\
\text { the association Bioconsom'acteur. As } \\
\text { incomes were declared in the } \\
\text { categories, the mean of each class was } \\
\text { used, while the arbitrary incomes were } \\
\text { determined for extreme classes. }\end{array}$ & $\begin{array}{l}\text { KANTAR } 2012 \text { and ad hoc } \\
\text { collection }\end{array}$ \\
\hline
\end{tabular}


clusters were evaluated after adjustment for multiple testing using the Dunnett's correction. SAS ${ }^{\circledR} 9.4$ software (SAS Institute Inc., Cary, NC, USA) was used to perform all the analyses. The RRR model was performed with the SAS procedure Proc PLS ${ }^{\circledR}$ and the clustering with the Proc Cluster ${ }^{\circledR}$ and Proc Fastclust ${ }^{\circledR}$.

\section{Results}

Overall, our sample was composed of 29,413 participants $(74.8 \%$ women). The average age was 53.5 years.

\subsection{Factor extraction}

The first and second RRR-extracted factors explained $20.25 \%$ and $6.04 \%$ of the total variation in the sustainability indicators and $9.29 \%$ and $8.67 \%$ of the total variation in food group consumption, respectively. The average (using 20 replications) Pearson correlation coefficients between the first and second factors of the RRR procedure extracted from the whole sample and from a random sample including half of the population were high (0.999 and 0.986 for the first and second factors, respectively).

Table 2 shows the correlation coefficient between the RRRextracted factors and the sustainability indicators. A positive correlation between the first RRR factor and the level of GHGEs, energy consumption and land occupation and negative correlations with the organic food consumption ratio and the PANDiet moderation sub-score were observed. The second RRR factor was positively correlated with the CED, organic food consumption ratio, share of budget dedicated to food and PANDiet adequacy sub-score. The correlations between the RRR factors and the food groups are presented in supplemental material 2.

\subsection{Cluster description}

The two-step clustering based on the first two RRR-extracted factors, allowed to identified six clusters, representing $3.90 \%$ (cluster 1), 17.05\% (cluster 2), 27.05\% (cluster 3), 23.06\% (cluster 4), $23.07 \%$ (cluster 5 ), and $5.86 \%$ (cluster 6 ) of the studied population. Sustainability indicators (Table 3), dietary (Fig. 1 and Supplemental material 3) and sociodemographic characteristics across the clusters (Table 4) are presented.

Participants from cluster 1 exhibited diets with the highest impacts on the environment as well as the lowest nutritional scores (except for the adequacy PANDiet sub-score) and were among the least affordable. These diets are characterized by the highest consumption of meat $(162.4 \mathrm{~g} / \mathrm{d}$ of ruminant meat and $129.5 \mathrm{~g} / \mathrm{d}$ of non-ruminant meat), the high consumption of dairy products (fresh and cheese) and sweet and fatty foods. In addition, their consumption of fruit and vegetables were low compared to the average consumption of the sample (562 vs. $729 \mathrm{~g} / \mathrm{d}$ ). This group was characterized by a lower proportion of women. Compared to the other clusters, a high proportion of participants were overweight (56\%), and many presented unhealthy lifestyles (tobacco use and/or elevated alcohol consumption).

The GHGEs, CED and land occupation related to the diets of participants in cluster 2 were high, although not the highest. These diets exhibited high nutritional quality, except for the PANDIET moderation sub-score. Indeed, their diets showed high food diversity with a standard consumption for all food groups (except for fresh dairy products). Participants in this cluster were the oldest. A

\footnotetext{
${ }^{1}$ Relative mean intake of each cluster shown as a percentage compared to the highest observed mean intake across the clusters for selected foods among the French sample.
}

Table 2

Explained variation in the consumption of food groups and sustainable indicators in correlation with unsustainable dietary pattern and greener dietary pattern (extracted from $\mathrm{n}=29,413$ ).

\begin{tabular}{lll}
\hline & Factor 1 & Factor 2 \\
\hline Explained variation in food groups ${ }^{\mathrm{a}}(\%)$ & 9.29 & 8.67 \\
Explained variation in sustainable indicators (\%) & 20.25 & 6.04 \\
\hline Pearson's correlation coefficients & X score 1 & X score 2 \\
\hline $\mathrm{CED}(\mathrm{MJ} / \mathrm{y})$ & 0.59 & 0.21 \\
Land occupation $\left(\mathrm{m}^{2} / \mathrm{y}\right)$ & 0.72 & -0.01 \\
GHGEs $\left(\mathrm{CO}_{2 \mathrm{eq}} / \mathrm{y}\right)$ & 0.76 & -0.02 \\
Organic food consumption ratio (\%) & -0.32 & 0.23 \\
Diet density (kcal/100 g) & 0.02 & -0.49 \\
PANDiet adequacy sub-score $(/ 100)$ & -0.01 & 0.33 \\
PANDiet moderation sub-score $(/ 100)$ & -0.28 & 0.06 \\
Share of budget to food $(\%)$ & 0.00 & 0.19 \\
\hline
\end{tabular}

CED: cumulative energy demand, GHGEs: greenhouse gas emissions and PANDiet: diet quality index based on the probability of adequate nutrient Intake.

a Food groups were adjusted for total energy intake using the residual method.

large proportion of the population was overweight. This cluster presented a low percentage of high alcohol drinkers $(6.74 \%)$ and smokers (7.16\%), and a high proportion of physically active participants.

The environmental impacts of the diets in cluster 3 were close to those of the diets in cluster 2. However, their diets presented lower nutritional quality but were more affordable. Indeed, participants on average had a lower budget for food than those participants in cluster 2 . The average consumption of food with animal origins was similar to cluster 2, but the consumption of sweet and fatty foods (144 g/d vs. $132 \mathrm{~g} / \mathrm{d})$, alcohol beverages (118 g/d vs. $101 \mathrm{~g} / \mathrm{d})$, and mixed diets (40 g/d vs. $33 \mathrm{~g} / \mathrm{d}$ ) was higher compared to the other groups. Participants in this cluster were younger in proportion and had a higher level of academic education than the participants in cluster 2 . In cluster 2 , no vegetarian or vegan diet was reported.

The diets of the participants in cluster 4 were characterized by low environmental impact compared to the other clusters. These participants had the most affordable diets, while organic food contribution to their diets was low. However, their diets were energy dense and presented low adequacy sub-score; indeed, the consumption of sweet and fatty products $(163 \mathrm{~g} / \mathrm{d})$, as well as starches (193 g/d), was high, while the consumption of vegetables, fruit $(477 \mathrm{~g} / \mathrm{d}$ ) and animal products ( $83 \mathrm{~g} / \mathrm{d}$ ) was low. Subjects in this cluster were more likely young, never smokers and sedentary.

Compared to the other clusters, the environmental impacts (greenhouse gas emissions and land occupation) related to the diets in cluster 5 were the lowest, and the nutritional quality was high. Additionally, the diets were affordable and exhibited a large proportion of organic food. These diets were characterized by high consumption of fruits, vegetables, starchy food and soya and low consumption of animal origin foods, particularly ruminant meats $(18.5 \mathrm{~g} / \mathrm{d})$. Subjects in this cluster were more likely to have higher educational level, physically active, and less often overweight than those in the other clusters. A high proportion of participants reported following a vegetarian (5.79\%) or vegan diet (3.08\%).

Diets in cluster 6 were characterized by the highest consumption of vegetable, fruits, soya, fish and whole grain foods, while they presented the lowest consumption of meats $(49 \mathrm{~g} / \mathrm{d})$, alcoholic beverages $(60 \mathrm{~g} / \mathrm{d})$, sweet and/or fatty foods $(83 \mathrm{~g} / \mathrm{d})$ and mixed dishes $(17 \mathrm{~g} / \mathrm{d})$. Therefore, these diets presented the highest nutritional quality, according to both the adequacy and moderation sub-scores. Environmental impacts related to the diet were low, except for CED. The share of the budget for food was high. Table 4 shows that the subjects in this cluster exhibited sociodemographic characteristics close to those in cluster 5 in terms of 


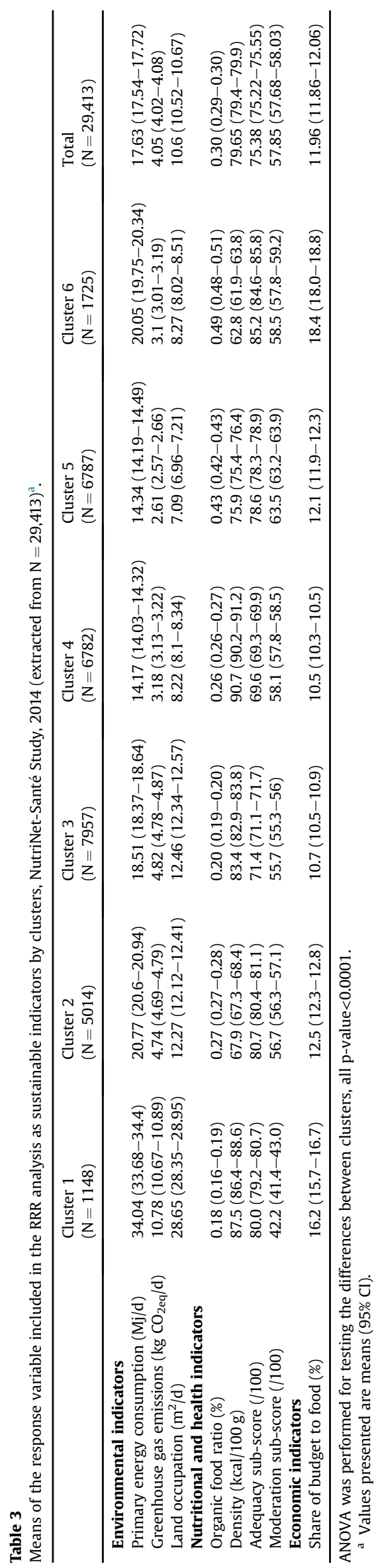

their income per household unit, body mass index and smoking status. However, they were older, had lower educational level. The proportion of women was higher than in cluster 5. Their lifestyles were particularly healthy.

\section{Discussion}

\subsection{Summary of findings}

To characterize the sustainability of the diets based on a multicriteria approach, we first used reduced rank regression for extracting two factors, which maximized the explanation of the sustainability indicators. The first factor mostly correlated with the environmental indicators, while the second was strongly and positively correlated with the nutritional quality and inversely correlated with the affordability. Then, the RRR-extracted factors were introduced in a clustering classification for identifying six clusters.

Cluster 1, which comprised a small percentage of the sample, displayed an unsustainable diet. Clusters 2 and 3 specifically impacted the environment. Finally, clusters 4,5 and 6 were composed of participants that presented the most eco-friendly diets. However, their diets are distinguished by their nutritional quality and affordability. The most affordable diets (cluster 4 versus cluster 6) had the lowest nutritional quality and vice versa. Finally, cluster 5 was a good compromise between the sustainability dimensions and was composed of $23.07 \%$ of the sample. It is noteworthy that the diets of cluster 5 were diversified but contained relatively low amounts of animal origin products (especially red meat) and substantial consumption of soya-based foods. Additionally, the consumption of whole products was high, while sweet and fatty product consumption was low.

\subsection{Animal-based foods as important contributors to diet-related environmental impacts}

Our results showed that the environmental impacts related to the diets of those who eat low quantities of meat are less important. Compared to the sample average, the diets of the sustainable cluster emitted 36\% less GHGEs, energy and land consumption are respectively $19 \%$ and $33 \%$ lower. The major contribution of animal products, specifically ruminant meat, to environmental impacts has already been well documented (Birt et al., 2017; Perignon et al., 2017; Aleksandrowicz et al., 2016; Hallström et al., 2015). In accordance with our results, the recent review, Aleksandrowicz et al. reported that the transition from a Western diet to an alternative diet containing less meat led to a $22 \%$ decrease in GHGEs, $28 \%$ decrease in land occupation and $18 \%$ decrease in water need (Aleksandrowicz et al., 2016). Recently, Briesbroek at al. applied a similar RRR analysis, with two explanatory variables: GHGE and a Dutch healthy diet index, to determine patterns that are both healthy and environmentally friendly in a sample of Dutch adult. A Plant-based pattern was identified whose GHGE were significantly lower compared to the average (Biesbroek et al., 2018). Another study found that low animal-based consumption diets as the Mediterranean diet needed $2.44 \%$ less energy than the national average diet (Pairotti et al., 2015). However, compared to our study, the methodology of diet assessment (food frequency questionnaire) and the life cycle assessment perimeter (without converting and transport) was different. Moreover, many previous studies have argued that the reduction of animal products in the diet presents also benefits for human health, diet monetary cost and others environmental aspects (Jones et al., 2016; Tilman and Clark, 2014). 


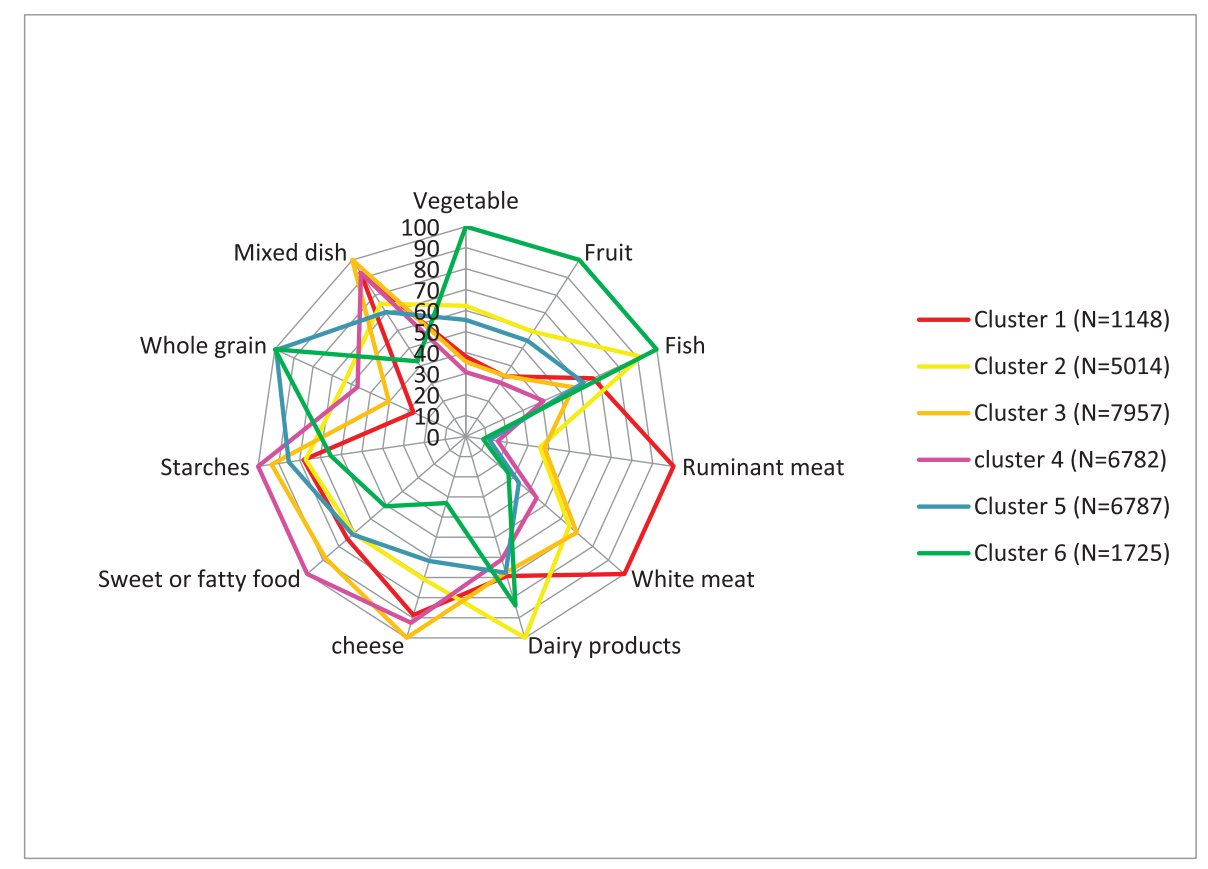

Fig. 1. Cluster association with selected intake food groups, NutriNet-Santé Study, 2014 (extracted from $N=29,413$ ). ${ }^{1}$

\subsection{Role of the other food groups in the sustainability of diets}

In clusters with low meat consumption, meat was replaced by other food. Indeed, clusters 5 and 6 exhibited high intake of fresh dairy products, fish, soya, vegetables, fruit and starches (including whole grains), while participants in cluster 4 preferentially consumed cheeses, starches and sweet or fatty food and exhibited diets with relatively poor nutritional quality. Previous studies concluded that reducing the consumption of high-calorie foods and alcohol should help for climatic change mitigation (Temme et al., 2015; van de Kamp et al., 2018) while decreasing the prevalence of chronic diseases related to poor nutrition diets (Birt et al., 2017; van de Kamp et al., 2018).

Diets in these three clusters (4,5 and 6) exhibited a lower environmental footprint than the three previous clusters. However, discrepancies in the environmental impacts emerged between clusters 4,5 and 6 . Indeed, the diets in clusters 5 and 6 needed more primary energy than the diets in cluster 4 , but indicators related to land occupation and GHGEs were more favourable. First, this result may be partly explained by the high consumption of fruits and vegetables in clusters 5 and 6 . Indeed, horticulture and market gardening require a large amount of energy, irrigation, fertilizers, phytosanitary protection, and the use of plastic contributed to the energy needed. However, such a hypothesis should be considered with caution since there is a wide source of variation in the energy demand according to the agricultural techniques (e.g., heated greenhouses) or seasonality (Cerutti et al., 2014; Hospido et al., 2009). Relevant techniques to produce fruits and vegetables could significantly decrease the environmental impact given that the consumption of fruit and vegetables is beneficial for health (Miller et al., 2017; Oyebode et al., 2014). A recent modelling study based on consumer behaviours investigated the substitutions induced by an increase in the consumption of fruits and vegetables (Irz et al., 2016). Their results showed that the guidelines related to the increase in fruit and vegetable consumption would have positive effects on the GHGEs and acidification. Indeed, a 5\% increase in the intake of fruit and vegetables would lead to a decrease in the consumption of dairy products and a switch between red meat and white meat (Irz et al., 2016). In this study, the impacts on the energy demand were not evaluated. A second potential explanation might be that participants in cluster 4 had lower calorie intake compared to clusters 5 and 6 . Indeed, several studies have shown that highcalorie intake is often connected to higher environmental impact (Perignon et al., 2017).

Of note, the consumption of fish in cluster 6 is high $(+37 \%$ compared to the sample average). Thus, while the diets of cluster 6 are favourable for the sustainable indicators considered in our study, most fishing practices are unsustainable and have an important biodiversity footprint (Downs and Fanzo, 2015; Villasante et al., 2012). In addition, some contaminants, such as heavy metals or organochlorine contaminants, accumulate in the adipose tissues or livers of fish and would contribute to increased dietary exposure to persistent chemicals in humans (Manger du poisson, 2017). European Public Health Association recommended consuming different species of fish and favouring oily fish from sustainable fishing grounds or aquaculture (Birt et al., 2017).

\subsection{Opposition between healthy and affordable diets}

In our study, the healthiest diets (cluster 6) were the least affordable (participants have to dedicate a higher part of their income) and the most expensive, while the cheapest and most affordable diets (cluster 4 ) were less healthy. Thus, the most sustainable diets of participants in cluster 5 are not the most expensive and least affordable. This result is inconsistent with an Australian study evaluating the affordability of a healthy and sustainable food basket in neighbourhoods with different socio-economic levels (according to a socio-economic index for areas score including income, employment or education (Barosh et al., 2014)). The authors reported that a healthy and sustainable basket was more expensive and less affordable in all the neighbourhoods included in the study (Barosh et al., 2014). These discrepancies with our findings may be explained by several hypotheses. First, in the Australian study, the healthy and sustainable basket was identified using a theoretical 
Table 4

Lifestyle and sociodemographic characteristics by cluster, NutriNet-Santé Study, 2014 (extracted from N=29,413) .

\begin{tabular}{|c|c|c|c|c|c|c|c|}
\hline & $\begin{array}{l}\text { Cluster } 1 \\
(\mathrm{~N}=1148)\end{array}$ & $\begin{array}{l}\text { Cluster } 2 \\
(\mathrm{~N}=5014)\end{array}$ & $\begin{array}{l}\text { Cluster } 3 \\
(\mathrm{~N}=7957)\end{array}$ & $\begin{array}{l}\text { Cluster } 4 \\
(\mathrm{~N}=6782)\end{array}$ & $\begin{array}{l}\text { Cluster } 5 \\
(\mathrm{~N}=6787)\end{array}$ & $\begin{array}{l}\text { Cluster } 6 \\
(\mathrm{~N}=1725)\end{array}$ & $\mathrm{P}^{\mathrm{b}}$ \\
\hline $\operatorname{Sex}(\%)$ & & & & & & & 0.06 \\
\hline Female & 55.31 & 79.90 & 69.62 & 73.65 & 79.61 & 82.20 & \\
\hline Male & 44.69 & 20.10 & 30.38 & 26.35 & 20.39 & 17.80 & \\
\hline \multirow[t]{2}{*}{ Energy intake (kcal/j) } & $2490(2454$ & $1932(1915$ & $1902(1889$ & $2025(2010$ & $1984(1970$ & $2301(2272$ & \\
\hline & $-2525)$ & $-1949)$ & $-1916)$ & $-2039)$ & $-1999)$ & $-2330)$ & \\
\hline Expenditure for the diet $(€ / \mathbf{j})$ & $\begin{array}{l}10.53(10.38 \\
-10.69)\end{array}$ & $8.4(8.32-8.47)$ & $7.06(7-7.12)$ & $\begin{array}{l}6.51(6.45 \\
-6.58)\end{array}$ & $\begin{array}{l}7.72(7.66 \\
-7.79)\end{array}$ & $\begin{array}{l}11.34(11.22 \\
-11.47)\end{array}$ & \\
\hline Age (\%) & & & & & & & $<0.0001$ \\
\hline$<25 y$ & 1.13 & 0.98 & 1.92 & 2.79 & 1.80 & 1.80 & \\
\hline $25-35 y$ & 6.79 & 4.71 & 12.66 & 16.31 & 9.68 & 6.32 & \\
\hline $35-50 y$ & 23.00 & 16.41 & 25.55 & 29.30 & 20.86 & 15.94 & \\
\hline $50-65 y$ & 42.86 & 44.14 & 36.72 & 31.39 & 40.77 & 46.26 & \\
\hline$\geq 65 \mathrm{y}$ & 26.22 & 33.77 & 23.15 & 20.22 & 26.89 & 29.68 & \\
\hline Scholar qualification (\%) & & & & & & & $<0.0001$ \\
\hline$<$ High-school diploma & 27.35 & 27.00 & 20.38 & 17.28 & 19.89 & 25.57 & \\
\hline High-school diploma & 16.38 & 15.64 & 14.33 & 14.20 & 14.25 & 15.01 & \\
\hline Post-secondary graduation & 56.27 & 57.36 & 65.29 & 68.52 & 65.86 & 59.42 & \\
\hline Monthly income per household unit ${ }^{\mathrm{C}}(\%)$ & & & & & & & 0.40 \\
\hline Refuse to declare & 5.31 & 6.84 & 5.39 & 5.43 & 6.62 & 7.83 & \\
\hline$<1200$ euros & 10.89 & 9.47 & 10.81 & 13.30 & 12.02 & 13.04 & \\
\hline $1200-1800$ euros & 24.74 & 21.56 & 23.25 & 24.45 & 22.50 & 22.14 & \\
\hline $1800-2700$ euros & 24.65 & 28.78 & 26.73 & 27.94 & 27.26 & 27.13 & \\
\hline$>2700$ euros & 34.41 & 33.35 & 33.82 & 28.89 & 31.60 & 29.86 & \\
\hline Living area (\%) & & & & & & & 0.06 \\
\hline Rural community & 23.61 & 21.76 & 22.92 & 21.05 & 22.55 & 23.78 & \\
\hline Urban unit: $<20,000$ inhabitants & 15.00 & 15.36 & 15.42 & 15.44 & 14.72 & 16.11 & \\
\hline Urban unit: 20,000 and 200,000 inhabitants & 18.67 & 20.04 & 17.39 & 18.89 & 19.83 & 17.77 & \\
\hline Urban unit: $>200,000$ inhabitants & 42.73 & 42.84 & 44.26 & 44.61 & 42.90 & 42.33 & \\
\hline Physical activity (\%) & & & & & & & $<0.0001$ \\
\hline $\operatorname{High}(>60 \mathrm{~min} / \mathrm{d})$ & 32.58 & 37.26 & 29.80 & 28.89 & 36.97 & 46.55 & \\
\hline Medium (30-60 min/d) & 31.01 & 34.36 & 36.56 & 38.10 & 37.98 & 31.59 & \\
\hline $\operatorname{Low}(<30 \mathrm{~min} / \mathrm{d})$ & 25.17 & 16.75 & 22.95 & 22.24 & 14.91 & 10.90 & \\
\hline Missing data ${ }^{\mathrm{d}}$ & 11.24 & 11.63 & 10.69 & 10.78 & 10.14 & 10.96 & \\
\hline Body mass index (BMI) (\%) & & & & & & & 0.05 \\
\hline $\mathrm{BMI}<18.50 \mathrm{~kg} / \mathrm{m} 2$ & 1.39 & 2.51 & 2.76 & 6.06 & 6.78 & 8.46 & \\
\hline $18.50-24.99 \mathrm{~kg} / \mathrm{m} 2$ & 42.16 & 52.53 & 58.25 & 66.18 & 68.22 & 63.48 & \\
\hline $25.00-29.99 \mathrm{~kg} / \mathrm{m} 2$ & 35.19 & 30.36 & 27.86 & 20.38 & 19.01 & 20.52 & \\
\hline $\mathrm{BMI} \geq 30.00 \mathrm{~kg} / \mathrm{m} 2$ & 21.25 & 14.60 & 11.12 & 7.39 & 6.00 & 7.54 & \\
\hline Tobacco status (\%) & & & & & & & $<0.0001$ \\
\hline Former smoker & 44.03 & 44.16 & 39.17 & 35.73 & 42.02 & 46.03 & \\
\hline Occasional smoker & 3.22 & 2.69 & 3.59 & 4.11 & 2.99 & 2.20 & \\
\hline Current smoker & 11.06 & 6.74 & 9.21 & 8.26 & 5.41 & 3.88 & \\
\hline Never smoker & 41.38 & 46.41 & 48.02 & 51.90 & 49.58 & 47.88 & \\
\hline Alcohol consumption status (\%) & & & & & & & $<0.0001$ \\
\hline No drinker & 5.66 & 5.54 & 3.80 & 4.29 & 6.65 & 11.88 & \\
\hline $\begin{array}{l}\text { Moderate drinker ( }<20 \mathrm{~g} / \mathrm{d} \text { for women and }<30 \mathrm{~g} / \\
\mathrm{d} \text { for men) }\end{array}$ & 82.40 & 87.30 & 86.44 & 85.90 & 85.84 & 81.80 & \\
\hline High drinker & 11.93 & 7.16 & 9.76 & 9.81 & 7.51 & 6.32 & \\
\hline Diet (\%) & & & & & & & $<0.0001$ \\
\hline Omnivorous & 100 & 99.92 & 100.00 & 97.05 & 91.13 & 88.41 & \\
\hline Vegan & 0 & 0.08 & 0.00 & 2.46 & 3.08 & 5.22 & \\
\hline Vegetarian & 0 & 0.00 & 0.00 & 0.49 & 5.79 & 6.38 & \\
\hline
\end{tabular}

${ }^{\text {a }}$ Values presented are the percentage or means $(95 \% \mathrm{CI})$.

b $\mathrm{P}$ values are based on the Mantel-Haenszel $\chi^{2}$ test.

c The median standard of living of people living in metropolitan France household is $1679 € /$ month.

d As some questions were optional, some data are missing.

approach based on the national guidelines, while we used observed diets. Moreover, we did not evaluate the food price according to the living area of participants, while this factor was accounted for in the Australian study. Finally, the diets of participants in cluster 5 were a compromise between the sustainable dimensions assessed in the study and may not be interpreted as the optimal sustainable diet.

\subsection{Organic consumption is linked to a healthy diet}

The results also showed a positive link between a healthy diet (clusters 5 and 6) and high consumption of organic food. Indeed, organic dietary patterns were often associated with high consumption of plant-based food (Baudry et al., 2015). Therefore, as in our sample, organic food consumers often exhibited a diet with a better nutritional quality, except concerning specific nutritional recommendations related to animal food consumption (Baudry et al., 2017; Eisinger-Watzl et al., 2015). Moreover, the diets of organic food consumers, which were mainly represented in clusters 5 and 6, exhibited low environmental impacts, which could be a consequence not only of the structure of the diet but also of the mode of production. Many studies agreed that organic farming compared to conventional farming reduces $\mathrm{N}$-surplus and pesticide 
use (Reganold and Wachter, 2016; Muller et al., 2017).

\subsection{Limitations and strengths of the study}

Some limitations of our study should be underlined. First, our results are based on a sample of volunteers involved in a long-term cohort focused on nutrition and health. Thus, caution is particularly needed when extrapolating the results to the overall population. It is likely that all behaviours are not represented, such as those of young people. Respondents were more often women postgraduates with healthy lifestyles. These characteristics have been shown to be key predictors of sustainable food consumption (Gilg et al., 2005; Panzone et al., 2016). A wider coverage of different behaviours in a representative population would help to ensure that alternative diets are acceptable in the general population. Second, the scope of the environmental impact evaluation did not include the phases of processing, transformation and transport, limiting the assessment of the impacts to the production step. However, most environmental impacts generally occur at the farm level (Weidema and Meeusen, 2000; Clune et al., 2017). The environmental database was based on farms that registered on a volunteer basis in DIALECTE, leading to potential nonrepresentativeness of actual French farms. However, we were able to differentiate organic and conventional modes of production. Moreover, since data from Kantar database are not available for two years post collection, there is a two years delay between the food price data and the dietary assessment that may lead to approximations in the diet monetary cost assessment. Finally, the dietary patterns identified may not be interpreted as the optimal because our results were based on observational data from a cohort of volunteers and compromised between many sustainable dimensions.

The RRR procedure allowed us to extract factors explaining our numerous sustainability indicators and to summarize the information for clustering. The use of this dimension-reducing method, based on the database structure, is particularly innovative and leads to less subjective decisions. However, the RRR procedure is not a completely a posteriori method because we had to arbitrarily select the indicators and the number of retained factors. The number of clusters retained was equally arbitrarily chosen, even if the dendrogram and statistical indicators drove our choice. The twostep clustering procedure offered advantages to stabilize the classification, in particular, for the boundary between the two cluster participants. Additionally, the large sample size enabled us to cover a diversity of eating habits and disseminated practices as more sustainable. Finally, the wide spectrum of accurate data allowed the use of a large variety of indicators, providing a thorough evaluation of the sustainability of the diet. In addition, we took into account the mode of production in the environmental assessment.

\section{Conclusion}

In conclusion, these results highlight that in the current agronomic and economic context, dietary patterns compatible with all sustainable dimensions were scarce, even in a cohort of participants that are potentially more sensitive to nutrition and to the environment. The study also revealed a cluster with almost $23 \%$ of the study sample who adopted diets with high compatibility with the sustainability indicators assessed in the study. These more sustainable diets varied are marked by moderate consumption of meat and low consumption of nutritionally poor food. Overall, oppositions between healthy, eco-friendly and affordable dietary pattern remain. It is necessary to identify and better understand these conflicts to help driving the future public health measures and further investigations will be needed to identify the levers and brakes for adoptions in the general population which remains a considerable challenge.

\section{Contributions of the authors}

All authors read and approved the final manuscript. LS, JB, L-GS, $\mathrm{SH}, \mathrm{BL}, \mathrm{PP}, \mathrm{DL}$ and EK-G designed and conducted the research; LS and EK-G analysed the data; and LS wrote the paper. LS, JB, BA, L-GS, $\mathrm{SH}, \mathrm{BL}, \mathrm{PP}, \mathrm{DL}$, and EK-G were involved in interpreting the results and editing the manuscript. LS and EK-G had a primary responsibility for the final content.

\section{Funding}

The NutriNet-Santé study is supported by the French Ministry of Health (DGS), the National Public Health Agency (Santé Publique France), the National Institute for Health and Medical Research (INSERM), the National Institute for Agricultural Research (INRA), the National Conservatory of Arts and Crafts (CNAM) and the University of Paris 13. This study was supported by the BioNutriNet Project, which is a research project supported by the French National Research Agency (Agence Nationale de la Recherche) in the context of the 2013 Programme de Recherche Systèmes Alimentaires Durables (ANR-13-ALID-0001). Louise Seconda is supported by a doctoral fellowship from the French Environment and Energy Management Agency (ADEME) and the National Institute for Agricultural Research (INRA). The authors declare no conflict of interest.

\section{Acknowledgements}

We especially thank our computer scientists Younes Esseddik, Paul Flanzy and Thi Hong Van Duong; our statisticians and data managers Veronique Gourlet, Fabien Szabo, Nathalie Arnault and Laurent Bourhis; and our dietician, Cédric Agaësse. We warmly thank all the dedicated and conscientious volunteers involved in the Nutrinet-Santé cohort. We also thank the Bioconsom'acteurs' members for price collection.

\section{References}

Aleksandrowicz, L., Green, R., Joy, E.J.M., Smith, P., Haines, A., 2016 Nov 3. The im-

pacts of dietary change on greenhouse gas emissions, land use, water use, and health: a systematic review. Wiley AS, editor PLoS One 11 (11), e0165797.

Aston, L.M., Smith, J.N., Powles, J.W., 2012. Impact of a reduced red and processed meat dietary pattern on disease risks and greenhouse gas emissions in the UK: a modelling study. BMJ Open 2 (5), e001072.

Auestad, N., Fulgoni, V.L, 2015 Jan 1. What current literature tells us about sustainable diets: emerging research linking dietary patterns, environmental sustainability, and economics. Adv. Nutr. Int. Rev. J. 6 (1), 19-36.

Barosh, L., Friel, S., Engelhardt, K., Chan, L., 2014 Feb. The cost of a healthy and sustainable diet - who can afford it? Aust. N. Z. J. Publ. Health 38 (1), 7-12.

Baudry, J., Méjean, C., Allès, B., Péneau, S., Touvier, M., Hercberg, S., et al., 2015 Oct 21. Contribution of organic food to the diet in a large sample of French adults (the NutriNet-Santé cohort study). Nutrients 7 (10), 8615-8632.

Baudry, J., Touvier, M., Allès, B., Péneau, S., Méjean, C., Galan, P., et al., 2016 Aug. Typology of eaters based on conventional and organic food consumption: results from the NutriNet-Santé cohort study. Br. J. Nutr. 116 (04), 700-709.

Baudry, J., Allès, B., Péneau, S., Touvier, M., Méjean, C., Hercberg, S., et al., 2017 Mar Dietary intakes and diet quality according to levels of organic food consumption by French adults: cross-sectional findings from the NutriNet-Santé Cohort Study. Publ. Health Nutr. 20 (04), 638-648.

Biesbroek, S., Monique Verschuren, W.M., van der Schouw, Y.T., Sluijs, I., Boer, J.M.A., Temme, E.H.M., 2018 Feb 16. Identification of data-driven Dutch dietary patterns that benefit the environment and are healthy. Clim. Change [Internet] 
[cited 2018 May 4]; Available from: http://link.springer.com/10.1007/s10584018-2153-y.

Birt, C., Buzeti, T., Grosso, G., Justesen, L., Lachat, C., Lafranconi, A., et al., 2017. Healthy and Sustainable Diets for European Countries. EUPHA (European Public Health Association).

Castañé, S., Antón, A., 2017 Nov. Assessment of the nutritional quality and environmental impact of two food diets: a Mediterranean and a vegan diet. J. Clean. Prod. 167, 929-937.

Cerutti, A.K., Beccaro, G.L., Bruun, S., Bosco, S., Donno, D., Notarnicola, B., et al., 2014 Jun. Life cycle assessment application in the fruit sector: state of the art and recommendations for environmental declarations of fruit products. J. Clean. Prod. 73, 125-135.

Clune, S., Crossin, E., Verghese, K., 2017 Jan 1. Systematic review of greenhouse gas emissions for different fresh food categories. J. Clean. Prod. 140 (Part 2), 766-783.

Craig CL, Marshall AL, Sjostrom M, Bauman AE, Booth ML, Ainsworth BE. International Physical Activity Questionnaire: 12-Country Re...: Medicine \& Science in Sports \& Exercise [Internet]. LWW. [cited 2016 Apr 28]. Available from: http:// journals.lww.com/acsm-msse/Fulltext/2003/08000/International_Physical Activity Questionnaire 20.aspx.

Darmon, N., Ferguson, E.L., Briend, A., 2002 Dec 1. A cost constraint alone has adverse effects on food selection and nutrient density: an analysis of human diets by linear programming. J. Nutr. 132 (12), 3764-3771.

van Dooren, C., Marinussen, M., Blonk, H., Aiking, H., Vellinga, P., 2014 Feb. Exploring dietary guidelines based on ecological and nutritional values: a comparison of six dietary patterns. Food Pol. 44, 36-46.

van Dooren, C., Tyszler, M., Kramer, G., Aiking, H., 2015 Sep 18. Combining low price, low climate impact and high nutritional value in one shopping basket through diet optimization by linear programming. Sustainability 7 (9), 12837-12855.

Downs, S.M., Fanzo, J., 2015 Dec. Is a cardio-protective diet Sustainable? A review of the synergies and tensions between foods that promote the health of the heart and the planet. Curr. Nutr. Rep. 4 (4), 313-322.

Eisinger-Watzl, M., Wittig, F., Heuer, T., Hoffmann, I., 2015 Jan 10. Customers purchasing organic food - do they live Healthier? Results of the German national nutrition survey II. Eur. J. Nutr. Food Saf. 5 (1), 59-71.

Gilg, A., Barr, S., Ford, N., 2005 Aug. Green consumption or sustainable lifestyles? Identifying the sustainable consumer. Futures 37 (6), 481-504.

Gustafson, D., Gutman, A., Leet, W., Drewnowski, A., Fanzo, J., Ingram, J., 2016 Feb 23. Seven food system metrics of sustainable nutrition security. Sustainability 8 (3), 196.

Hallal, P.C., Victora, C.G., 2004 Mar. Reliability and validity of the international physical activity questionnaire (IPAQ). Med. Sci. Sports Exerc. 36 (3), 556.

Hallström, E., Carlsson-Kanyama, A., Börjesson, P., 2015 Mar 15. Environmental impact of dietary change: a systematic review. J. Clean. Prod. 91, 1-11.

Hercberg, S., Castetbon, K., Czernichow, S., Malon, A., Mejean, C., Kesse, E., et al. 2010. The Nutrinet-Santé Study: a web-based prospective study on the relationship between nutrition and health and determinants of dietary patterns and nutritional status. BMC Publ. Health 10, 242.

Hoffmann, K., 2004 May 15. Application of a new statistical method to derive dietary patterns in nutritional epidemiology. Am. J. Epidemiol. 159 (10), 935-944.

Hospido, A., Milà i Canals, L., McLaren, S., Truninger, M., Edwards-Jones, G., Clift, R 2009 Jul. The role of seasonality in lettuce consumption: a case study of environmental and social aspects. Int. J. Life Cycle Assess. 14 (5), 381-391.

Irz, X., Leroy, P., Réquillart, V., Soler, L.-G., 2016 Oct. Welfare and sustainability effects of dietary recommendations. Ecol. Econ. 130, 139-155.

Jones, A.D., Hoey, L., Blesh, J., Miller, L., Green, A., Shapiro, L.F., 2016 Jul. A systematic review of the measurement of sustainable diets. Adv. Nutr. Int. Rev. J. 7 (4), 641-664.

van de Kamp, M.E., Seves, S.M., Temme, E.H.M., 2018 Dec. Reducing GHG emissions while improving diet quality: exploring the potential of reduced meat, cheese and alcoholic and soft drinks consumption at specific moments during the day. BMC Publ. Health [Internet] 18 (1) [cited 2018 May 4]. Available from: https:// bmcpublichealth.biomedcentral.com/articles/10.1186/s12889-018-5132-3.

Kesse-Guyot, E., Castetbon, K., Touvier, M., Hercberg, S., Galan, P., 2010. Relative validity and reproducibility of a food frequency questionnaire designed for French adults. Ann. Nutr. Metab. 57 (3-4), 153-162.

Lee, A.J., Kane, S., Ramsey, R., Good, E., Dick, M., 2016 Dec. Testing the price and affordability of healthy and current (unhealthy) diets and the potential impacts of policy change in Australia. BMC Publ. Health [Internet] 16 (1). Available from: http://bmcpublichealth.biomedcentral.com/articles/10.1186/s12889-016-2996y [cited 2017 Nov 22].

Manger du poisson: pourquoi? comment?|Anses - Agence nationale de sécurité sanitaire de l'alimentation, de l'environnement et du travail [Internet]. [cited 2017 Sep 28]. Available from:: https://www.anses.fr/fr/content/manger-dupoisson-pourquoi-comment.

Miller, V., Mente, A., Dehghan, M., Rangarajan, S., Zhang, X., Swaminathan, S., et al, 2017 Aug 29. Fruit, vegetable, and legume intake, and cardiovascular disease and deaths in 18 countries (PURE): a prospective cohort study. Lancet [Internet [cited 2017 Sep 13]; Available from: http://www.sciencedirect.com/science]
article/pii/S0140673617322535.

Monsivais, P. Scarborough, P. Lloyd, T., Mizdrak, A., Luben, R., Mulligan, A.A, et al., 2015 Jan 7. Greater accordance with the Dietary Approaches to Stop Hypertension dietary pattern is associated with lower diet-related greenhouse gas production but higher dietary costs in the United Kingdom. Am. J. Clin. Nutr. 102 (1), 138-145.

Muller, A., Schader, C., El-Hage Scialabba, N., Brüggemann, J., Isensee, A., Erb, K.-H., et al., 2017 Dec. Strategies for feeding the world more sustainably with organic agriculture. Nat. Commun. [Internet] 8 (1) [cited 2017 Nov 24]. Available from: http://www.nature.com/articles/s41467-017-01410-w.

Nutrinet-Santé, E., 2013. Table de composition des aliments de l'étude NutrinetSanté. Paris Econ.

Organisation Mondiale de la Santé (OMS). International Classification of adult underweight, overweight and obesity according to BMI [Internet]. [cited 2017 Sep 27]. Available from:: http://apps.who.int/bmi/index.jsp?introPage=intro_3. html.

Oyebode, O., Gordon-Dseagu, V., Walker, A., Mindell, J.S., 2014 Sep. Fruit and vegetable consumption and all-cause, cancer and CVD mortality: analysis of Health Survey for England data. J. Epidemiol. Community Health 68 (9), 856-862.

Pairotti, M.B., Cerutti, A.K., Martini, F., Vesce, E., Padovan, D., Beltramo, R., 2015 Sep. Energy consumption and GHG emission of the Mediterranean diet: a systemic assessment using a hybrid LCA-IO method. J. Clean. Prod. 103, 507-516.

Panzone, L., Hilton, D., Sale, L., Cohen, D., 2016 Aug. Socio-demographics, implicit attitudes, explicit attitudes, and sustainable consumption in supermarket shopping. J. Econ. Psychol. 55, 77-95.

Perignon, M., Vieux, F., Soler, L.-G., Masset, G., Darmon, N., 2017 Jan. Improving diet sustainability through evolution of food choices: review of epidemiological studies on the environmental impact of diets. Nutr. Rev. 75 (1), 2-17.

Reganold, J.P., Wachter, J.M., 2016 Feb 3. Organic agriculture in the twenty-first century. Nat. Plants 2 (2), 15221.

Sáez-Almendros, S., Obrador, B., Bach-Faig, A., Serra-Majem, L., 2013. Environmental footprints of Mediterranean versus Western dietary patterns: beyond the health benefits of the Mediterranean diet. Environ. Health 12, 118.

Scarborough, P., Appleby, P.N., Mizdrak, A., Briggs, A.D.M., Travis, R.C., Bradbury, K.E., et al., 2014 Jul. Dietary greenhouse gas emissions of meat-eaters, fish-eaters, vegetarians and vegans in the UK. Clim. Change 125 (2), 179-192.

Schofield, W., 1984 Dec. Predicting basal metabolic rate, new standards and review of previous work. Hum. Nutr. Clin. Nutr. 39 (Suppl. 1), 5-41.

Seconda, L., Baudry, J., Allès, B., Hamza, O., Boizot-Szantai, C., Soler, L.-G., et al., 2017 Jan 12. Assessment of the sustainability of the mediterranean diet combined with organic food consumption: an individual behaviour approach. Nutrients 9 (1), 61.

Seconda, L., Baudry, J., Allès, B., Boizot-Szantai, C., Soler, L.-G., Galan, P., et al., 2018. Comparing nutritional, economic and environmental performances of diets according to their levels of Greenhouse Gases Emissions. Clim. Change. https:// doi.org/10.1007/s10584-018-2195-1. Available from:

Solagro [Internet]. [cited 2017 Apr 13]. Available from: http://dialecte.solagro,org/.

Soret, S., Mejia, A., Batech, M., Jaceldo-Siegl, K., Harwatt, H., Sabaté, J., 2014 Jul 1. Climate change mitigation and health effects of varied dietary patterns in reallife settings throughout North America. Am. J. Clin. Nutr. 100 (Suppl. 1), 490S-495S.

Springmann, M., Godfray, H.C.J., Rayner, M., Scarborough, P., 2016 Apr 12. Analysis and valuation of the health and climate change cobenefits of dietary change. Proc. Natl. Acad. Sci. 113 (15), 4146-4151.

Sustainable diets and Biodiversity - Directions and solutions for policy, research and action - i3004e.pdf [Internet]. [cited 2016 May 12]. Available from:: http:// www.fao.org/docrep/016/i3004e/i3004e.pdf.

Temme, E.H., Toxopeus, I.B., Kramer, G.F., Brosens, M.C., Drijvers, J.M., Tyszler, M., et al., 2015 Sep. Greenhouse gas emission of diets in The Netherlands and associations with food, energy and macronutrient intakes. Publ. Health Nutr. 18 (13), 2433-2445.

Tilman, D., Clark, M., 2014 Nov 27. Global diets link environmental sustainability and human health. Nature 515 (7528), 518-522.

Treu, H., Nordborg, M., Cederberg, C., Heuer, T., Claupein, E., Hoffmann, H., et al., 2017. Carbon footprints and land use of conventional and organic diets in Germany. J. Clean. Prod. [Internet]. Available from: http://linkinghub.elsevier. com/retrieve/pii/S0959652617309666.

Verger, E.O. Mariotti, F. Holmes, B.A., Paineau, D. Huneau, J.F. 2012 Aug 3. Evaluation of a diet quality index based on the probability of adequate nutrient intake (PANDiet) using national French and us dietary surveys. PLoS One 7 (8), e42155.

Villasante, S., Morato, T., Rodriguez-Gonzalez, D., Antelo, M., Österblom, H., Watling, L., et al., 2012 Dec. Sustainability of deep-sea fish species under the European union common fisheries policy. Ocean Coast Manag. 70, 31-37.

Weidema, B., Meeusen, M.J.G., 2000. Agricultural Data for Life Cycle Assessments. La Hague, Pays-Bas, p. 189.

Willett, W., Stampfer, M.J., 1986 Jul. Total energy intake: implications for epidemiologic analyses. Am. J. Epidemiol. 124 (1), 17-27. 